\title{
En torno a los fundamentos filosóficos de la psicología positiva
}

Reynaldo Alarcón

Universidad Ricardo Palma

Lima, Perú

\author{
Recibido: 1 de junio del 2017 / Aceptado: 13 de julio del 2017 \\ doi: https://doi.org/10.26439/persona2017.n20.1737
}

El presente artículo busca analizar el marco filosófico en el que se apoya la psicología positiva, asumiendo que tras una corriente psicológica subyace un sistema de supuestos teóricos que representan su filosofía de la ciencia. Ontológicamente, se afirma que el sujeto investigado por la psicología positiva es el ser humano, y solo él y su experiencia subjetiva, expresada a través de sus comportamientos. Desde el punto de vista epistemológico, esta nueva corriente psicológica es una ciencia empírica que adopta el modelo hipotético-deductivo, que permite decidir cuándo un conjunto de afirmaciones tiene o no contenido científico. La antropología filosófica de la psicología positiva ha sido influenciada por la psicología humanística, y considera que el hombre es una criatura única e irrepetible que busca el florecimiento y óptimo funcionamiento del potencial psíquico inherente a su naturaleza.

marco filosófico / ontología / epistemología / antropología filosófica

\section{Philosophical Foundations of Positive Psychology}

This paper aims to establish the philosophical framework in which Positive Psychology bases its theoretical assumptions and its view as a philosophy of science. From an ontological standpoint, human beings are the entities investigated through their subjective experience, which is expressed through their behaviors. From the epistemological standpoint, this novel model of psychology is an empirical science, which adopts the hypothetical-deductive model, to determine if its claims have scientific content. From the philosophical anthropology standpoint, Positive Psychology has been influenced by Humanistic Psychology, which considers that humans are unique and unrepeatable beings, who flourish and strive to optimize their inherent psychological potential.

philosophical framework / ontology / epistemology / philosophical anthropology

Correo electrónico: reynaldo.alarcón.n@hotmail.com 


\section{INTRODUCCIÓN}

La psicología positiva aparece en el panorama de la psicología internacional a comienzos del tercer milenio. Fue presentada por dos distinguidos psicólogos, Martin E. P. Seligman y Mihály Csíkszentmihályi, en la revista American Psychologist (2000). En su artículo, describen la psicología positiva como "la ciencia de la experiencia subjetiva de los rasgos positivos individuales". Asimismo, indican que busca mejorar la calidad de vida y el funcionamiento óptimo del ser humano.

La psicología positiva, como ciencia básica, investiga las condiciones y procesos que contribuyen al florecimiento óptimo de la gente (Gable y Haidt, 2005); en tanto que, como ciencia aplicada, utiliza los hallazgos de la investigación psicológica positiva para facilitar el óptimo funcionamiento de los rasgos positivos individuales (Linley y Joseph, 2004). Con el fin de llevar a cabo estas intervenciones, desarrolla tecnologías psicológicas: instrumentos de medición psicológica, psicoterapias y programas de intervención.

El anuncio formal, o partida de nacimiento del nuevo movimiento psicológico, condensa las aspiraciones e inquietudes de un grupo de investigadores que, desde pocas décadas atrás, trabajaban en algunos de esos temas, olvidados por la psicología dominante. Su periodo de gestación había terminado y era el momento de anunciar a la comunidad psicológica internacional el nacimiento de una nueva corriente psicológica denominada psicología positiva. No emerge en el panorama en contra de ninguna corriente psicológica, como a menudo ha ocurrido; tampoco busca romper lanzas con paradigmas teóricos o metodológicos, aunque se adhiere a algunos y critica duramente a otros. No es una revolución científica en el sentido propuesto por Kuhn (1992), que reemplaza completamente, o en parte, el paradigma vigente por otro nuevo. Aparece para tratar áreas del psiquismo humano tradicionalmente marginadas, $\mathrm{y}$ lo hace con metodología científica.

En la presentación de la psicología positiva, Seligman y Csíkszentmihályi (2000) llaman la atención sobre el hecho de que la psicología, desde la Segunda Guerra Mundial, había devenido en una ciencia concentrada en reparar el daño inferido al comportamiento normal, dentro de un modelo del funcionamiento humano alterado: ansiedad, frustración, agresividad, histerias, fobias, temores, traumas, cólera, tristeza, obsesiones y otros tantos desórdenes mentales generados como secuela de la guerra. La atención que recibieron tales problemas en la investigación y en el desarrollo de programas de intervención puede explicarse porque se requería urgente tratamiento psicológico o psiquiátrico para los miles de ciudadanos excombatientes, que quedaron con profundas alteraciones psicológicas. Se dedicaron fondos especiales para la investigación y la atención de estos pacientes, por lo que la psicología clínica atrajo la atención de los gobiernos y de las universidades, particularmente en Estados Unidos. Miles de psicólogos se entrenaron en clínica y encontraron ocupación en la Administración de Veteranos que ofrecía 
este tipo de servicios. "La guerra hizo que la psicología creciera más de prisa, e ideara un nuevo rol público que definió a la psicología estadounidense. Tras la guerra, los psicólogos comenzaron a practicar masivamente la psicología clínica en USA" (Leahey, 1999).

Las observaciones de los fundadores de la psicología positiva sobre el sesgo psicopatológico que tomó la psicología de posguerra no sugieren abandonar la investigación de comportamientos negativos, puesto que el avance del conocimiento del mundo psicopatológico siempre será necesario para superar las dolencias del sufrimiento humano. Por esto, señala Seligman que la psicología positiva es un complemento de la psicopatología, pero no su sustituto.

Sin embargo, no toda la psicología del periodo posterior a la Segunda Guerra Mundial centró su interés en el estudio de comportamientos de orden psicopatológico. Basta con recordar las amplias investigaciones sobre análisis experimental de la conducta y terapia conductual de Skinner y sus seguidores en América y Europa; y el redescubrimiento en Norteamérica de la psicología cognitiva de Piaget y su epistemología genética, difundida en el curso de los años sesenta y siguientes. La teoría de la disonancia cognitiva de Festinger generó numerosas investigaciones en los años cincuenta y sesenta; en tanto que la psicología transcultural buscaba identificar las constancias y diferencias en el comportamiento de los individuos de culturas diferentes. La psicología humanista, fundada por Rogers $\mathrm{y}$
Maslow, estaba interesada en desarrollar el potencial latente que poseen los seres humanos, en busca de su realización como personas.

La originalidad de la psicología positiva reside en que focaliza su actividad en áreas inexploradas del psiquismo humano, conectadas con el bienestar psicológico, la realización del individuo como persona y el desarrollo de virtudes cívicas para vivir en armonía en una sociedad plural, que son temas de nuestro tiempo no abordados por las psicologías precedentes y que son tratados por la nueva orientación psicológica con procedimientos científicos. $\mathrm{La}$ nueva corriente presenta ideas novedosas que abren sugestivos horizontes y temas para la investigación psicológica básica y aplicada. He aquí algunos: esperanza, optimismo, felicidad, coraje, sensibilidad estética, perdón, perseverancia, espiritualidad, amor, sabiduía, altruismo, tolerancia, gratitud, amor, talento, sensibilidad estética. En suma, lo que busca la psicología positiva es el bienestar y la autorrealización de la persona.

\section{EL PROBLEMA}

La finalidad de este trabajo es ofrecer un bosquejo de los fundamentos filosóficos en los que se apoya la psicología positiva. Abordamos los siguientes temas: (a) establecer, desde el punto de vista ontológico, la naturaleza del objeto o de los objetos que investiga; (b) exponer la epistemología o teoría del conocimiento en que se basan sus hallazgos; y (c) explicar la antropología filosófica o idea del hombre que asume esta corriente. Los 
temas citados corresponden a la filosofía de la ciencia que, mutatis mutandis, son los de la filosofía de la ciencia, conceptuada la psicología como disciplina científica.

El examen de los temas propuestos constituye, en realidad, un ensayo, puesto que muy poco se ha escrito en forma sistemática sobre los fundamentos filosóficos de la psicología positiva. Ciertamente, observan Bunge y Ardila (1988): "La investigación científica, tanto en psicología como en cualquier otro campo del conocimiento, no se conduce en un vacío filosófico, sino sobre el fondo de un complejo marco filosófico de referencia" (p. 38).

\section{EL AMBIENTE PSICOLÓGICO EN LA GÉNESIS DE LA PSICOLOGÍA POSITIVA}

Estimamos que no solo fue el énfasis hacia los comportamientos negativos la causa que generó la aparición de la psicología positiva. A este factor, que indudablemente es de primer orden, hay que sumar motivaciones de orden teórico. Recordemos que la psicología siempre ha sido una disciplina donde han estado presentes los desencuentros respecto a la demarcación de sus dominios (el alma, la conciencia, la conducta) y a sus métodos de investigación (la introspección, la intuición, la observación externa, el experimento). Wundt, en 1879, introdujo el método experimental en el área de la psicología para hacer de ella una ciencia natural y sacarla del seno de la filosofía. Esto condujo, hacia fines del siglo XIX, a la reacción de Dilthey, quien clasificó las ciencias en ciencias de la naturaleza y ciencias del espiritu. La pri- mera, siguiendo el modelo de las ciencias naturales, busca explicar el acontecer psíquico mediante la relación causal de un cierto número de elementos, valiéndose del método experimental y de hipótesis. En cambio, "ni las hipótesis ni las relaciones causales son necesarias en las ciencias del espíritu", arguyó Dilthey (1945), y entre ellas ubicó a la psicología. Consideraba que la psicología no necesita de conceptos subyacentes logrados por inferencia inductiva para establecer una conexión, pues la vida psíquica está enlazada en una conexión originalmente dada, uniforme como un todo, que es vivenciada de modo inmediato. La conexión uniforme a la que se refiere Dilthey son las formas del acontecer interno, captadas y comprendidas introspectivamente. El concepto de comprensión es de gran importancia en la psicología de este filósofo, quien enérgicamente afirmó que a la naturaleza la explicamos y a la vida psíquica la comprendemos (Dilthey, 1945, pp. 223-328).

Más adelante, en 1913, Watson critica duramente a Wundt, al punto de señalar que, en los treinta años transcurridos desde la instalación de su laboratorio de psicología experimental, se había probado que la psicología introspectiva se fundaba sobre hipótesis falsas, y que ninguna psicología que incluyese el problema religioso mente-cuerpo podría alcanzar resultados verificables. "La psicología científica debe basarse en lo que podemos observar [cursivas del autor], y lo que se puede observar es la conducta [cursivas del autor], esto es, 'lo que el organismo hace o dice"" (Watson, 1955). Esa fue la partida de nacimiento del conductismo, 
revisado en años posteriores por Skinner. La dura crítica de Watson hacia la obra de Wundt encontró asidero en que mantuvo a la "conciencia" como objeto de su investigación y a la introspección como método, en su modalidad de introspección experimental, que el profesor de Leipzig conservó en su sistema.

La psicología de la forma o de la estructura(Gestaltheorie), de Wertheimer, Köhler, Koffka y Lewin, aparece en Alemania a principios del siglo xx como reacción a la insuficiencia de la psicología atomista-asociacionista, que, siguiendo el camino de las ciencias de la naturaleza, había logrado encontrar como últimos elementos de los cuerpos átomos, moléculas y células. Similarmente, los psicólogos creyeron hallar en la "sensación" el último elemento de la conciencia, irreductible a todo esfuerzo posterior de análisis. Para dar orden a los elementos, recurrieron a las antiguas leyes de la asociación formuladas por Aristóteles. Sin embargo, la psicología de la forma asumió, después de cuidadosas investigaciones experimentales, que lo que percibimos en el mundo no son elementos aislados, sino estructuras o todos organizados. Nuestra vida psíquica es una totalidad, y se asume una interpretación monista regida por principios y leyes (Dilthey, 1945; Dilthey, 1956).

Köhler (1948) critica el conductismo que, llevado por su excesiva preocupación de objetividad, "mutila lastimosamente el objeto de la psicología al excluir el testimonio de la conciencia [cursivas del autor], que considera la porción más entrañable de la vida psíquica". Debido a que el vocablo conciencia ha perdido valor científico, Köhler (1948) propone utilizar el término experiencia directa ("sensación de darse cuenta") en vez de conciencia (p. 25).

La breve referencia de los hechos correspondientes a la evolución histórica de la psicología muestra que esta disciplina ha avanzado a través de la crítica, a menudo ácida y dogmática, pero tantas veces fecunda para generar nuevas opciones. Se ha criticado el objeto de la psicología, sus métodos de investigación y también a los sujetos de investigación, hombres o animales; algunos psicólogos con la pretensión científica muy elevada sustituyeron al hombre por animales menores y extrapolaron sus hallazgos para explicar el comportamiento humano. La psicología ha avanzado en términos dialécticos de contradicciones y negaciones; de esta manera, casi siempre, nos hemos encontrado simultáneamente con varios sistemas psicológicos vigentes, al punto que se habló de psicologías, en plural, y no de una psicología. En vista de esta situación, en las últimas décadas del siglo XIX y hacia fines del siglo pasado, se propusieron algunos paradigmas unificadores de la psicología para superar las antinomias internas, pero el siglo $\mathrm{xx}$ terminó sin lograrse la unificación esperada.

A mediados del siglo pasado y en los años siguientes, las corrientes psicológicas más influyentes en Estados Unidos eran el conductismo operante de Skinner, el psicoanálisis ortodoxo de Freud, y la psicología humanista, considerada como la "tercera fuerza", liderada por Maslow, Rogers, Bugental y otros. A 
estas tendencias hay que sumar la psicología cognitiva de Piaget, que empezaba a irrumpir en ese panorama psicológico, en el cual se gestó la psicología positiva. La revisión de los temas de estas corrientes psicológicas: sus métodos de investigación y las filosofías que orientaron sus trabajos, será útil para obtener una idea más comprensiva del contexto ideológico en el que germina la psicología positiva, que es el tema central. Esto nos lleva a examinar los enfoques teóricos del conductismo, el psicoanálisis y la psicología humanista, en lo que tienen de común o contradictorio con la psicología positiva, así como en los temas relativos a la filosofía de la psicología.

\section{El CONDUCtISMO OperANTE de SkINNER}

\section{La conducta como objeto de la psicología}

Hacia 1912, Watson (1955) manifestó que los psicólogos objetivistas lograron por unanimidad determinar que el objeto de la psicología es la conducta, definida como "lo que el organismo hace o dice". Con énfasis afirmó que había que limitarse a lo observable y a formular leyes relativas a estas cosas. Considera, también, que la psicología es "una ciencia natural que se arroga todo el campo de las adaptaciones humanas", y "su compañera más íntima es la fisiología". Su meta es la descripción y el control de la conducta, y una conducta solo es comprensible después de someterla a control experimental (pp. 25-30).

Skinner acogió dentro de su sistema, el conductismo operante, los siguientes elementos del conductismo watsoniano: la conducta de los organismos como objeto de la investigación psicológica, el método experimental, el diseño estímulorespuesta, y su rechazo de la conciencia del ámbito de la psicología. Sin embargo, Skinner, el más renombrado continuador del conductismo, se aparta en mucho de las ideas del fundador. Critica a Watson al sostener que sus experimentos eran una investigación de la actividad fisiológica de la corteza cerebral; también, porque hizo interpretaciones precipitadas al afirmar que "el pensamiento es simplemente habla sub-vocal". Bajando el tono de su crítica, observa que los defectos de la explicación de Watson son ahora, principalmente, de carácter histórico (Skinner, 1975). La postura antifisiológica de Skinner es muy clara: sostiene que el comportamiento puede explicarse solo por datos conductuales, sin recurrir a la fisiología ni a otras fuentes, incluida la estadística.

El conductismo operante buscó describir la conducta a partir de variables observables: estímulo y respuesta. Resulta fácil advertir que renuncia a considerar los procesos mentales internos o "mundo debajo de la piel", como los denominó Skinner (1975); no niega la existencia de los hechos privados, aunque cuestiona la naturaleza del objeto observado y la confiabilidad de las observaciones. Pero ¿qué hay debajo de la piel? La respuesta la ofrece el mismo Skinner: sensaciones, hábitos, opiniones, estados de ánimo, decisiones, percepciones, pensamientos, virtudes, instintos, voluntad, creencias, ideas, recuerdos, deseos, intereses, conciencia, actitudes, ansiedad, deseos, 
sabiduría, expectativas, impulsos. En suma, todo el repertorio de características psicológicas que conforman el mundo psíquico del hombre, según la psicología mentalista (Skinner, 1975), quedó fuera de la investigación psicológica.

Limitar el conocimiento psicológico a datos empíricamente observables conduce a reducir la psicología a un empirismo estrecho que limita la investigación solo a uno de sus componentes: la conducta manifiesta, la cual es generada por procesos mentales internos que no son tomados en consideración, no obstante que lo interno y lo externo son dos dimensiones de la realidad psicológica humana, que es una unidad inextricable, separada solo para efectos de análisis. El que una corriente psicológica opte por una de estas dimensiones no pasará de ofrecer un cuadro incompleto de la vida psíquica del ser humano. Los procesos mentales y la conducta, como una totalidad, es el objeto de la psicología científica contemporánea. Refiriéndose a este tema, opina Llinás (1985) que el conductismo adopta una ontología naturalista, limitada a estudiar la conducta de los organismos, dejando de lado procesos no observables, que son propiamente psíquicos.

Bunge y Ardila (1988) advierten que la gnoseología del conductismo es realista, puesto que se esfuerza por explicar un aspecto de la realidad, cuya existencia admite desde el momento en que exige que la investigación sea objetiva ( $p$. 82). El pensamiento conductista llega a un empirismo gnoseológico extremo cuando sostiene que la validez de todo conocimientoradica solo en la experiencia.
Seguidor de esta filosofía, el conductismo rechaza utilizar proposiciones hipotéticas, quedándose en la observación empírica. Por esto, se afirma que el conductismo se conforma con una gnoseología primitiva, evita hipótesis y teorías, es decir, construcciones inmediatamente no observables, rehuyendo el problema de ponerlos a prueba (Bunge, 1985, pp. 135-136).

Los hechos empíricamente observables constituyen, ciertamente, el fundamento del conocimiento, pues representan parte de la realidad y a partir de ellos se inicia el conocimiento científico, de allí su importancia gnoseológica en la construcción de teorías científicas. El dato empírico es valioso, pero no suficiente; en efecto, las teorías científicas contienen constructos teóricos, debido a que se refieren a objetos o propiedades que no son directamente observables por los sentidos, solo conocemos su existencia por medio de las consecuencias observables (Piscoya, 1987). Los seres humanos, muy a menudo, hacemos inferencias acerca de los procesos mentales de otros individuos. Lo que sabemos de los pensamientos y de los sentimientos de otras personas en la vida cotidiana lo inferimos de su conducta. La inferencia a partir de la conducta es un juicio que se apoya en datos significativos obtenidos a través de una experiencia prolongada en el tiempo. "El conocimiento de la conducta es un conocimiento de hecho, en tanto que el conocimiento científico de los procesos mentales es teórico o inferido" (Hebb, 1968). Ambos son importantes. El conductismo utiliza la observación y la experimentación, describe y predice hechos observados, 
pero no explica hechos inaccesibles a la observación externa. Por esto, desde parámetros de la filosofía de la ciencia, su método de investigación es más limitado, y sus objetivos, más estrechos.

Cerrando los límites de sus fronteras, el conductismo operante rechaza toda forma de explicación mentalista y proclama, con énfasis, que la conducta es el objeto de la psicología. Su trabajo lo orienta a desarrollar novedosas tecnologías para controlar la conducta, predecirla y modificarla. La pertinaz actitud de Skinner de hacer del conductismo una ciencia autónoma se manifiesta en su renuencia a establecer conexiones con otras disciplinas científicas, particularmente con la fisiología del cerebro y el sistema nervioso central, puesto que podrían conducir a la desaparición de la psicología como ciencia independiente (Skinner, 1975). Boakes y Halliday (1974), que se adhieren a algunos puntos de vista del conductismo, sostienen que Skinner tenía confianza en establecer una ciencia basada por completo en datos conductuales. Su trabajo, ciertamente científico, sea por la rigurosidad del control experimental que imprimió a sus investigaciones, sea por la confianza en desarrollar una ciencia fundada en datos experimentales, dejó abierto un incitante problema en disputa: explicar la conducta humana con base en extrapolaciones procedentes directamente de la rata blanca o la paloma de laboratorio (Boakes y Halliday, 1974, pp. 211-246). ¿Poseerán confiabilidad y validez los hallazgos extrapolados, obtenidos en animales inferiores, para explicar la conducta humana? La respuesta de Skinner (1970) es parsimoniosa; observa que "la conducta humana se distingue por su complejidad, variedad y grandes realizaciones, pero no por ello los procesos básicos deben ser necesariamente diferentes" (p. 62). $\mathrm{Su}$ sugerencia encuentra fundamento en que "las leyes generales del aprendizaje son las mismas para cualquier organismo, sea cual sea su especie" (Bayés, 1970, p. 20). Trabajos posteriores de psicólogos no conductistas han puesto en evidencia que las leyes del aprendizaje son específicas para cada especie. Aún más, si fuese verdadera la afirmación conductista, sus hallazgos podrían generalizarse solamente a "procesos básicos" del comportamiento, principalmente en el aprendizaje, quedando pendiente todo el mundo interno "escondido bajo la piel", que el conductismo marginó de la psicología científica. Todo esto nos conduce a mirar con suma reserva la pretensión de explicar la conducta humana por extrapolación de hallazgos obtenidos en animales inferiores. ¿Por qué no explicar el comportamiento humano por sus procesos internos y sus manifestaciones observables?

\section{La conexión E-R}

El interés de la investigación conductista, reducida solo al análisis de la conducta, encontró en la conexión E-R (estímulo-respuesta) su paradigma ideal de investigación. La respuesta $(\mathrm{R})$ es generada por acción del estímulo precedente (E) y es predecible por esa estimulación; en otras palabras, el estímulo determina la respuesta. Este modelo no hace referencia a la intervención de procesos mentales internos, explora conductas 
reflejas típicas de organismos inferiores y es adecuada para investigaciones que tienen como sujetos de estudio a animales inferiores (ratas blancas y palomas), que son los preferidos de la investigación conductual. La conexión E-R, denominada caja negra, con terminales de entrada y salida, satisface las exigencias de la filosofía empirista y es útil para el conocimiento de conductas elementales. Posee alta generalidad descriptiva, no rebasa la descripción de los fenómenos y se abstiene de introducir variables intermedias importantes para la ampliación del conocimiento científico (Bunge, 1972).

\section{El pSicoanálisis ortodoxo de Freud}

El psicoanálisis de Freud es una corriente de larga data en los ambientes académicos psiquiátricos y psicológicos, en la literatura y en la pintura. Ha ejercido fecunda influencia en diversos sectores intelectuales, aunque no ha tenido favorable acogida en los círculos científicos, calificándosele de seudociencia (Bunge, 1985). El término psicoanálisis aparece en el escenario académico en 1900, año en que Freud publica su libro La interpretación de los sueños. Este término designa, en primer lugar, un método de exploración de los procesos inconscientes que traspasan la conciencia, y que era desconocido por la psicología dominante de aquellos tiempos.

El psicoanálisis asume que el comportamiento actual es determinado por la historia de la infancia de una persona y por el carácter de la vida afectiva que influye sobre el comportamiento. Los impulsos sexuales reprimidos, procedentes de la infancia, generan conflictos no resueltos y proporcionan una fuerza motriz suficiente para la formación de síntomas negativos. La visión de Freud sobre la vida psíquica es negativa; en sus construcciones teóricas predominan represiones sexuales, traumas, perversiones, fantasías incestuosas e instintos libidinosos que desembocan en un reduccionismo sexual. Freud (1982) afirma, reiteradamente, que en la raíz de la formación de cualquier síntoma se ha de encontrar experiencias traumáticas en la temprana vida sexual. En este sentido, la historicidad y las experiencias tempranas son extremadamente valiosas para la explicación de la conducta de los individuos, según el psicoanálisis.

El psicoanálisis parte de la idea epicúrea de que el hombre busca el placer y trata de evitar el dolor y el sufrimiento. Esta dualidad la representa a través de dos instintos básicos que operan en el proceso vital: los instintos de vida (Eros), como expresión de placer y perpetuación de la especie, a los que contrapone el instinto de muerte y destrucción (Thanatos). Las experiencias placenteras dan origen al principio del placer, al cual se opone el principio de la realidad, como medio racional que actúa como represor de los instintos negativos para superar las dificultades con que tropezaría el individuo en su adaptación al mundo. Una buena adaptación a la realidad se consigue cuando se prefiere soportar un dolor pasajero a cambio de un sufrimiento mayor, o quien se priva de algún placer para evitar sus consecuencias desagradables. Para Marcuse 
(1970), según la teoría freudiana, la historia del hombre es la historia de su represión: la cultura restringe su existencia social y también biológica, no solo partes del ser humano, sino su estructura instintiva en sí misma. Esta restricción, según Marcuse (1970), es precondición para la civilización; el Eros incontrolado es tan fatal como su mortal contrapartida, el instinto de la muerte. Más adelante agrega: "El animal hombre llega a ser humano solo por medio de una fundamental transformación de su naturaleza que afecta no solo las aspiraciones instintivas, sino también los valores instintivos, esto es, los principios que gobiernan la realización de estas aspiraciones" (pp. 26-27).

La idea del hombre, según Freud, es la de un ser dominado por el instinto sexual; su figura simbólica es la de un ser erotizado en constante inhibición de su libido, que le genera sufrimientos; pero, a la vez, la represión lo humaniza y el animal hombre llega a ser humano, se civiliza en tanto aprende a restringir sus instintos: reprime el Eros y también las fuerzas destructivas de Thanatos. Esto significa que la civilización empieza cuando la satisfacción de los instintos es reprimida y el principio del placer es sustituido por el principio de la realidad. Para el psicoanálisis, la cultura y los más altos valores de la cultura occidental son, en esencia, contenidos represivos, siendo imposible concebir una cultura no represiva.

Al hecho traumático de reemplazar el placer por la realidad, se suma la falta de libertad y sufrimiento, generados por la represión o modificación de los impulsos primarios. A estos eventos hay que añadir el concepto de felicidad, según el psicoanálisis. Sentencia Freud (1982) que el hombre y la sociedad no son felices y que quizás no puedan serlo; el maestro vienés reduce la felicidad a la satisfacción del instinto sexual. El amor sexual, afirma, "nos proporciona la experiencia placentera más poderosa y subyugante, estableciendo el prototipo de nuestras aspiraciones de felicidad" (p. 26). Pero el encuentro con la felicidad tropieza con la represión de la libido impuesta por el mundo exterior, que impide su satisfacción y, por ende, nos priva de ser felices. Por esto, dice Freud (1982): "Jamás nos hallamos tan a merced del sufrimiento como cuando amamos; jamás somos tan desesperadamente infelices como cuando hemos perdido el objeto amado o su amor". Siguiendo el pensamiento freudiano, la cultura actúa como barrera contra las pulsiones libidinosas y recorta las posibilidades de alcanzar la felicidad. Señala que la felicidad, impuesta por el principio del placer, es irrealizable, pero no por eso se deben abandonar los esfuerzos para acercarse a su realización. Arguye Freud, ampliando su encuentro con la felicidad, que el amor sexual no agota su búsqueda; se puede hallar la felicidad en el goce de la belleza, en las formas de gestos humanos, en los paisajes de la naturaleza, o en las creaciones artísticas. En el trasfondo de estas expresiones artísticas sustitutivas, se encuentran instintos sexuales latentes, según el psicoanálisis. En investigaciones recientes sobre variables generadoras de la felicidad, definidas como "satisfacción con la vida" y "estar subjetivamente bien", las respuestas que 
obtuvieron las más altas frecuencias fueron gozar de buena salud, tener una buena familia, estar bien con Dios. No se mencionaron variables relativas a la satisfacción sexual.

Honorio Delgado, el psiquiatra peruano que difundió tempranamente el psicoanálisis en América Latina, y que después de larga militancia se apartó de esa doctrina, publicó un artículo a la muerte de Freud, en el que afirma: "La práctica del psicoanálisis desde hace casi un cuarto de siglo nos ha permitido tanto aquilatar cada vez con mayor precisión la fecundidad del punto de vista dinámico psicogenético, cuanto reconocer el desenfreno de gran parte de las explicaciones freudianas" (Delgado e Iberico, 2005, p. 392). En suma: el método psicoanalítico y los hallazgos obtenidos han sido duramente cuestionados desde parámetros del método científico. Sin embargo, llama la atención que los seguidores del psicoanálisis ortodoxo no hayan podido demostrar la validez científica de su doctrina, más allá de pretender rechazar las críticas de sus opositores sin argumentos científicos.

\section{LA PSICOLOGÍA HUMANÍSTICA}

En el curso de los años cincuenta y sesenta, se gestó en Estados Unidos un movimiento psicológico de refinado nivel académico, que surgió como crítica y protesta en contra del psicoanálisis de Freud, por su determinismo biológico, y del conductismo operante de Skinner, por su concepción mecanicista del hombre. Su interés se centró en el estudio de la persona humana, conceptuada como ser único e irrepetible, su existencia y sus valores; en el hombre sano y no en el enfermo, como lo hacía el psicoanálisis; en el potencial humano creativo, y no en el reactivo, como lo hacía el conductismo. $\mathrm{Su}$ investigación se orientó a buscar el sentido y significación de la existencia humana (Quitmann, 1989; Auer, 1997; Child, 1975; Alarcón, 2009).

La psicología humanística apareció en Estados Unidos en 1961 con la publicación del Journal of Humanistic Psychology; un año después, se fundó la American Association of Humanistic Psychology, bajo la presidencia de Abraham Maslow. Reunía relevantes figuras del mundo psicológico, como Carl Rogers, Charlotte Bühler, Rollo May, James Bugental, Kurt Goldstein, Erich Fromm, Gordon Allport y Ruth Cohn. Algunos de ellos eran distinguidos psicólogos judío-alemanes, que huyendo de la persecución nazi se habían establecido en ese país. En la psicología humanística se enrolaron psicólogos y psiquiatras con similares intereses por la naturaleza humana, que procedían de filosofías afines surgidas en Europa. Las filosofías que alentaron el movimiento humanístico fueron el existencialismo de Heidegger, Buber, Jaspers, Sartre, Marcel; así como la fenomenología de Husserl y Merleau-Ponty. También estuvieron presentes filosofías orientales, como el taoísmo y el budismo zen. A la influencia de filosofías y psicologías europeas, se sumaron terapias del mismo origen: la terapia centrada en el cliente, de Rogers, traída a Europa por Reinhard y AnneMarie Tausch; la terapia de la Gestalt, de Perls; el psicodrama, de Moreno; el análisis 
transaccional, de Berne; la logoterapia, de Frankl, y la terapia integrativa, de Petzold.

La influencia europea, particularmente alemana, en la psicología humanística norteamericana es muy evidente, al punto que algunos autores europeos la definen como una ciencia fenomenológica de la experiencia humana, que tiene raíces en Husserl, fundador de la fenomenología, y en Heidegger, quien desarrolló la fenomenología existencial (Auer, 1997).

Nunca se habían reunido bajo una misma bandera académica tantas ideas conectadas con propósitos similares, tantos psicólogos y filósofos de corrientes afines y de tantas nacionalidades. En la psicología humanística convergieron variadas corrientes psicológicas y filosóficas, unidas por similares propósitos, pero la singularidad de cada una dificultó vertebrar una teoría unívoca, por lo que el resultado fue una confederación de ideas del más alto nivel del pensamiento psicológico y filosófico. No obstante, superando las diferencias, es posible identificar algunos rasgos comunes de este movimiento referidos en particular al concepto del hombre. (a) El ser humano es un organismo que funciona como una totalidad, es una Gestalt, su característica es la integración de la persona. (b) La integración se manifiesta en la unidad psicobiológica, cuyas entidades se influyen recíprocamente, y también hay unidad entre el pasado y el futuro, que le da continuidad a la vida. (c) El ser humano tiene la capacidad de reaccionar ante los estímulos de su entorno, pero también de distanciarse de ellos y orientarse hacia metas; el hombre es un ser pasivo y activo que puede modificar su entorno, tomar decisiones y asumir responsabilidades. (d) El ser humano necesita autonomía e independencia para su crecimiento personal, pero la autarquía tiene límites que son puestos por determinantes sociales; la libertad personal termina donde empiezan los derechos de los demás. (e) La naturaleza humana posee una tendencia básica a la autorrealización, conlleva la posibilidad para desarrollarse en dirección a una madurez plena y a un funcionamiento psíquico creciente (Maslow, 1989).

Maslow, una de las figuras importantes de este movimiento, critica con insistencia a la psicología que trata exclusivamente el sector negativo de la personalidad humana, pues considera que a través de ella se obtiene una imagen distorsionada de la totalidad del psiquismo humano y una visión disminuida del hombre. No niega la cara negativa del ser humano, sean el dolor, la muerte y aquello que reprime o niega la naturaleza esencial del ser humano. Empero, focaliza su interés en lo bueno, en todo lo que contribuye a la realización de la naturaleza interna del ser humano. La autorrealización ocupa el primer lugar en la jerarquía valorativa de las necesidades humanas; significa la actualización de las potencialidades de la persona, de todo lo que puede llegar a ser (Maslow, 1989; Quitmann, 1989).

La epistemología de la psicología humanística estaba muy lejos del enfoque científico de la investigación psicológica. Rechazaba la experimentación y la estadística para tratar datos psicológicos $\mathrm{y}$ concedía poco crédito a la información recogida con test psicológicos. El 
principio de objetividad, que es norma suprema en la investigación científica, es rechazado por la psicología humanística, que postula la identificación del investigador con el objeto que investiga, a partir de la visión unitaria de la persona y su mundo, "ser-en-el-mundo". Se vuelve contra la exigencia científica de objetividad, insiste en que el ser humano que investiga tiene que ser siempre parte de la investigación sobre el ser humano. La psicología humanística, inspirada en la fenomenología de Husserl, considera que nuestras vivencias constituyen la base de todo conocimiento, y que estas son aprehendidas mediante la "intuición eidética"; así este conocimiento adquiere significación universal y absoluta. La visión de las esencias (Wesenschau) consiste en aprehender la esencia a través de la experiencia vivida; es un conocimiento concreto, pero, a través de él, se aprehende, además del hecho contingente, una estructura inteligible que se impone cada vez que se piensa en el objeto intencional. De esta manera, se consigue un conocimiento que es válido para todos, posee significación universal y absoluta (Merleau-Ponty, 1964).

La psicología humanística básicamente se apoya en la fenomenología y en el existencialismo. También ha recurrido a técnicas psicológicas tradicionales, como son las autobiografías, la entrevista personal, el estudio de un caso, la empatía o capacidad para identificarse y vivenciar las emociones y sentimientos de otras personas. El ideario de la psicología humanística entró en abierta pugna con las ideas de la tradición científica de la psicología norteamericana, históricamente influida por la filosofía pragmática y la epistemología neopositivista. Por eso, era muy difícil que avanzara, sustentada en corrientes filosóficas opuestas, como el existencialismo y la fenomenología, que le servían de trasfondo teórico. Maslow se esforzó en señalar que la nueva orientación psicológica no pretendía confrontar a la psicología tradicional; particularmente se refería al conductismo de Skinner. El movimiento humanístico fue perdiendo vigor y se detuvo. La psicología humanística enriqueció a la psicología con nuevas construcciones teóricas que colocaron al ser humano en un lugar central.

\section{LA PSICOLOGÍA POSITIVA}

\section{El punto de vista ontológico}

Los autores de la psicología positiva, Seligman y Csíkszentmihályi (2000), afirman que es una ciencia de la experiencia subjetiva. Esta construcción de antigua data en la psicología mentalista alude a procesos que ocurren en el cerebro y se expresan a través de conductas. Suele denominárseles eventos internos o experiencia privada, porque corresponden al mundo interno del individuo. Skinner los llamó mundo debajo de la piel y los proscribió de la investigación científica. La psicología positiva ha recuperado el vasto terreno que ocupa la experiencia subjetiva haciéndola objeto de la investigación científica.

Desde el punto de vista de la ontología, el objeto de investigación de la psicología positiva es el ser humano y su experiencia subjetiva, expresada a 
través de comportamientos. Esto quiere decir que es una ciencia del ser humano y que sus hallazgos proceden de investigaciones basadas en su mundo interno. La diferencia entre la psicología positiva y el conductismo operante reside en que la primera investiga el mundo interno del ser humano, mientras que el segundo se ocupa de la conducta de animales menores. La psicología positiva, inspirada en la Gestalttheorie, considera al ser humano como un organismo que funciona como un todo; supera la antigua dualidad psicofísica, abriendo la posibilidad de analizar variables medioambientales y culturales para lograr una explicación más comprensiva del comportamiento humano.

El punto de encuentro entre la psicología positiva y el psicoanálisis está en que ambos se interesan por el mundo interno; sin embargo, el mundo interno tiene niveles: el dominio de la psicología positiva es el mundo consciente y para el psicoanálisis es el inconsciente. Freud se interesó por el submundo de experiencias negativas. La psicología positiva busca optimizar el desarrollo de las potencialidades humanas con miras a la realización de las personas.

\section{EPISTEMOLOGÍA DE LA PSICOLOGÍA POSITIVA}

\section{El paradigma $E-O-R$}

La conexión E-R que utiliza el conductismo de Skinner resulta insuficiente para analizar comportamientos complejos, es decir, cuando hay retardo entre el estímulo y la respuesta, lo que hace necesario introducir variables mediadoras que co- necten $\mathrm{E}$ con $\mathrm{R}$. ¿Con qué se llena el vacío entre E-R? Al recibir un estímulo, pensamos antes de dar una respuesta y surgen ideas que ocupan un periodo de tiempo; luego se ofrece la respuesta. Hebb (1968) lo denomina proceso mediador y lo define "como una actividad del cerebro que puede retener la excitación producida por un acontecimiento sensorial después que este ha cesado, permitiendo que el estímulo ejerza su efecto algún tiempo después" (p. 82). La función del proceso mediador (O) es conectar E con R. En consecuencia, el modelo adopta la fórmula E-O-R (estímulo, organismo, respuesta). Es conocido como modelo hipotético-deductivo. El conocimiento obtenido con inclusión de procesos mentales mediadores, no observables, es teórico e inferido; su paradigma de investigación admite hipótesis y teorías de tipo "caja traslúcida". De otro lado, el diseño E-R conductista conduce a un conocimiento de hechos observables: el estímulo determina la respuesta (Hebb, 1968; Bunge, 1985). Sobre estos datos, se establecen generalizaciones que representan teorías de tipo "caja negra" y el punto de vista del conocimiento empírico.

Ambos modelos de investigación son científicos; sin embargo, el modelo hipotético-deductivo posee mayor poder explicativo y es más apropiado en la investigación psicológica con humanos. Las teorías de la "caja traslúcida" no consideran la conducta como algo último, e intentan explicarla en términos de la constitución y estructura de los sistemas concretos de los que se ocupan; por eso, introducen construcciones hipotéticas que vinculan los inputs y los ouputs 
observables (Bunge, 1972). En las teorías de la "caja traslúcida", la abstracción no es derivada del objeto mismo, sino de la construcción hipotética.

Desde el punto de vista epistemológico, la psicología positiva ha adoptado el modelo hipotético-deductivo como instrumento conceptual, para organizar y articular el conocimiento científico, y como criterio de demarcación, que permita determinar cuándo una teoría es científica y cuándo no lo es (Popper, 1973; Piscoya, 2000). Este modelo ha alcanzado una amplia difusión e influido en el aspecto metodológico de la investigación psicológica. Asimismo, el término verificación de hipótesis ha sido sustituido por contrastación de hipótesis (falsifikation) propuesto por Popper.

La psicología positiva aplica en sus investigaciones el amplio repertorio metodológico que emplea la investigación psicológica actual: diseños experimentales, cuasiexperimentales, e investigaciones ex post facto (estudios exploratorios, descriptivos y correlacionales). Recoge sus datos con test psicológicos, inventarios, escalas, cuestionarios y entrevistas personales. Para el análisis de datos, hace uso de tratamientos estadísticos sofisticados. También utiliza, con menor frecuencia, el método cualitativo.

\section{La antropología filosófica de la psicología positiva}

Toda psicología humana parte de una idea acerca de lo que es el hombre, idea que reposa en una particular concepción filosófica del ser humano. La pregunta “¿qué es el hombre?" ha obtenido diversas respuestas mediante la reflexión en torno al ser humano. Estas ideas, según Scheler (1960 [1928]), provienen de tres fuentes dispares e irreconciliables. Primero, el círculo de ideas de la tradición judeo-cristiana, que concibe al hombre como un ser creado por Dios. Segundo, el círculo de ideas de la antigüedad clásica, de orden filosófico, que sostiene la tesis de que el hombre posee razón, logos, ratio, mens; por estos atributos tiene conciencia de sí mismo, posee palabra y la facultad de aprehender el porqué de todas las cosas. Tercero, el círculo de ideas de la ciencia moderna de la naturaleza, según el cual el hombre sería un producto final y muy tardío de la evolución del planeta Tierra. Ciertamente, el problema es complejo, pero aquí solamente nos interesa saber cuál es la idea del hombre según la psicología positiva, y compararla con las ideas sostenidas por el conductismo de Skinner, el psicoanálisis de Freud y la psicología humanista.

La psicología positiva conceptúa al hombre como una criatura buena que posee fuerzas latentes, las cuales constituyen sus virtudes y fortalezas que pueden actuar como escudos o amortiguadores contra del desarrollo de trastornos del comportamiento. No niega la existencia de factores negativos, pero asume que al lado de ellos existen factores positivos que contribuyen al florecimiento óptimo del ser humano. Asume que el bienestar y el vivir mejor no dependen de la suerte ni de la herencia, sino del individuo; al fracaso, el desaliento y el pesimismo puede oponérseles el optimismo, que se puede aprender a través de programas de entrenamiento 
intensivo (Seligman, 2004). Busca promover el mejoramiento de la calidad de vida y prevenir psicopatologías a través de los rasgos positivos y el desarrollo de cualidades positivas. Por eso, el aprendizaje de conductas positivas y competencias de prevención resulta muy fructífero para el desarrollo personal y para enfrentar situaciones adversas. La propuesta de la psicología positiva es alcanzar la felicidad y la realización del ser humano.

Seligman y Csíkszentmihályi (2000) sostienen que el comportamiento humano no es determinado por un historial de premios y castigos, como propone el conductismo. Las causas del comportamiento humano se hallan en acontecimientos mentales, como el pensar y la voluntad. Antes de realizar una acción, primero pensamos y posteriormente fuerzas psíquicas internas impulsan al individuo a la acción. Lo que llamamos las acciones voluntarias forman parte del linaje humano.

A diferencia del conductismo, que considera al hombre un ser pasivo, que responde a estímulos, la psicología positiva asume que el hombre no es solo un ser reactivo, sino que puede tomar sus propias decisiones, hacer selecciones y establecer preferencias, que aprende habilidades para liberarse de sentimientos de impotencia, que puede ejercer control de sus propias acciones y determinar su destino. Las acciones mencionadas conllevan un trasfondo voluntario, término utilizado por la antigua psicología mentalista que rescata la psicología positiva.

Conexa a la capacidad de libre decisión se encuentra la doctrina filosófica del libre albedrio, que enfatiza la capacidad humana de autodeterminar sus propias acciones y de elegir entre varias opciones. La expresión liberum arbitrium se ha tomado como sinónimo de libertad, y también como posibilidad de elegir entre el bien y el mal; en siglos pasados, suscitó apasionados debates filosóficos y religiosos entre la omnipotencia divina y la libertad humana (Ferrater Mora, 1969). Seligman (2004) introduce el libre albedrío en el marco teórico de la psicología positiva, argumentando que es un hecho de la naturaleza humana con base científica y es una realidad psicológica y biológica. La inclusión del libre albedrío busca darle sustento filosófico a la psicología positiva (p. 376).

Las corrientes filosóficas humanistas colocan al hombre en el centro de su interés, pero existe una variedad de humanismos; el más cercano a las características de la psicología positiva es el humanismo científico. Este busca el bienestar y la realización plena del ser humano, proclama la solidaridad entre los hombres sin discriminación alguna, y conceptúa que la ciencia es un valor social que debe estar al servicio del hombre y de la humanidad. Aboga por la vigencia de los valores bási$\cos$, que se resumen en el respeto a la vida y la libertad del hombre; intenta formar científicos con sensibilidad a los problemas del entorno social, y que compartan valores e inquietudes. Conceptúa que la ciencia y la tecnología son patrimonios de la humanidad; proclama la utilización de los resultados de la investigación para una vida humana más justa (Ferrater Mora, 1969; Mata Cabrera, 2003). 


\section{RefERENCIAS}

Alarcón, R. (2009). Psicología de la felicidad. Introducción a la psicología positiva. Lima: Universidad Ricardo Palma.

Auer, H. (1997). Psicología humanística (vol. 1). Lima: Universidad Femenina del Sagrado Corazón.

Bayés, R. (1970). Introducción a la edición castellana. En B. F. Skinner, Ciencia y conducta humana. Una psicología cientifica (pp. 13-28). Barcelona: Fontanella.

Boakes, R. A., y Halliday, M. S. (1974). El análisis skinneriano de la conducta. En N. Chomsky, S. Toulmin, J. Watkins y otros (Eds.), La explicación en las ciencias de la conducta. Madrid: Alianza Editorial.

Bunge, M. (1972). Teoría y realidad. Barcelona: Ariel.

Bunge, M. (1985). Epistemología. Barcelona: Ariel.

Bunge, M., y Ardila, R. (1988). Filosofía de la psicología. Barcelona: Ariel.

Child, I. L. (1975). Psicología humanística y la tradición experimental. México D. F.: Limusa.

Delgado, H., e Iberico, M. (2005). Psicología (10. ${ }^{\text {a }}$ ed.). Lima: Universidad Peruana Cayetano Heredia.

Dilthey, W. (1945). Ideas acerca de una psicología descriptiva y analítica (1894). En W. Dilthey, Psicología y teoría del conocimiento (pp. 223-328). México D. F.: Fondo de Cultura Económica.
Dilthey, W. (1956). Introducción a las ciencias del espiritu. Madrid: Revista de Occidente.

Ferrater Mora, J. (1969). Diccionario de filosofía (vol. 1). Buenos Aires: Sudamericana.

Freud, S. (1982). Obras completas. Buenos Aires: Amorrortu Editores.

Gable, S. L., y Haidt, J. (2005). What (and Why) is Positive Psychology? Review of General Psychology, 9(2), 193-110.

Hebb, D. O. (1968). Psicología (2. ${ }^{a}$ ed.). México D. F.: Interamericana.

Köhler, W. (1948). Psicología de la forma. Buenos Aires: Argonauta.

Kuhn, T. S. (1992). La estructura de las revoluciones cientificas. México D. F.: Fondo de Cultura Económica.

Leahey, T. H. (1999). Historia de la psicología. Madrid: Prentice Hall.

Linley, P. A., y Joseph, S. (2004). Applied Positive Psychology: A New Perspective for Professional Practice. En P. A. Linley y S. Joseph (Eds.), Positive Psychology in Practice (pp. 3-12). Hoboken, NJ: Wiley.

Llinás, A. R. (1985). Psicología y filosofía. En M. Bunge, Epistemología (pp. 129139). Barcelona: Ariel.

Marcuse, H. (1970). Eros y civilización. Barcelona: Seix Barral.

Maslow, A. (1989). El hombre autorrealizado. Hacia una psicología del ser. Barcelona: Herder.

Mata Cabrera, F. (2003). El humanismo científico y tecnológico desde la 
perspectiva de la sostenibilidad. Ingenierías, 6, 18-23.

Merleau-Ponty, M.(1964). Signos. Barcelona: Seix-Barral.

Piscoya, L. (1987). La investigación cientifica y educacional. Lima: Amaru Editores.

Piscoya, L. (2000). Tópicos en epistemología. Lima: Universidad Inca Garcilaso de la Vega.

Popper, K. (1973). La lógica de la investigación científica. Madrid: Tecnos.

Quitmann, H. (1989). Psicología humanistica. Barcelona: Herder.

Scheler, M. (1960 [1928]). El puesto del hombre en el cosmos. Buenos Aires: Losada.
Seligman, M. E. P. (2004). Aprenda optimismo. Barcelona: Debolsillo.

Seligman, M. E. P., y Csíkszentmihályi, M. (2000). Positive Psychology: An Introduction. American Psychologist, 55(1), 5-14.

Skinner, B. F. (1950). Are Theories of Learning Necessary? Psychological Review, 57, 193-216.

Skinner, B. F. (1970). Ciencia y conducta humana. Barcelona: Fontanella.

Skinner, B. F. (1975). Sobre el conductismo. Barcelona: Fontanella.

Watson, J. B. (1955). El conductismo (2. ${ }^{\mathrm{a}}$ edición). Buenos Aires: Paidós. 